\title{
Crianças COM e SEM SíndRome de DOWN ${ }^{1}$ : valores e CREnÇAS DE PAIS E PROFESSORES \\ Children With and Without DOWn Syndrome: parental and teacher \\ VALUES AND BELIEFS
}

\author{
Nara Liana PEREIRA-SILVA ${ }^{2}$ \\ Maria A uxiliadora DESSEN ${ }^{3}$
}

RESU M O : os valores e as crenças de pais e professores permeiam as práticas de cuidados e socialização das crianças e se expressam nas atividades rotineiras em que el as se engajam com seus diversos cuidadores. Este estudo descreve os valores e as crenças de 10 famílias e 10 professoras a respeito dos seguintes aspectos do desenvolvimento de crianças com e sem síndrome de Down: desenvolvimento motor, escolarização, profissionalização, relações íntimas e expectativas quanto ao futuro. As famílias eram compostas por pai, mãe e filhos, sendo que, em cinco delas, havia uma criança com síndrome de Down e, nas outras cinco, todas as crianças tinham desenvolvimento típico. Os dados foram col etados na residência das famílias, tendo sido realizadas entrevistas semi-estruturadas com os genitores e aplicado um questionário de caracterização do sistema familiar. Já as professoras foram entrevistadas no próprio local detrabal ho. Os resultados mostraram diferenças nos valores e crenças relatados pel os genitores de crianças com e sem síndrome de Down, especialmente no que se refere ao desenvolvimento motor do filho. As professoras relataram mudanças no desempenho acadêmico das crianças, bem como em seus relacionamentos sociais. Enquanto as professoras do ensino especial esperam progressos nos resultados acadêmicos, em longo prazo, as professoras do ensino regular esperam resultados mais imediatos de suas crianças com desenvolvimento típico. Os dados indicam al gumas similaridades entre as crenças de pais e professoras, as quais acreditam que o apoio e o envolvimento da família podem propiciar à criança com síndrome de Down os avanços necessários ao seu desenvolvimento.

PA LA V RA S-CH A VE: síndrome de Down; educação especial; valores; crença; família.

A BSTRACT: parental and teacher values and beliefs permeate the care and socialization practices of children and are expressed in the daily activities that children engage in with their various caretakers. This study describes the values and beliefs of 10 families and 10 teachers in relation to some aspects of the development of children with and without Down syndrome, such as motor development, academic performance, preparation for work, social and intimate relationships and expectation for the future. The families were composed of both parents and their offspring; fivefamilies had onechild with Down syndrome and the other five had all children with typical development. The data were collected in the families' homes and the parents participated in semi-structured interviews and answered a questionnaire about the characterization of the family system. The teachers were interviewed in their workplace. The results showed some differences in the values and beliefs reported by the parents of children with and without Down syndrome, particularly in relation to the child's motor development. The teachers reported changes in the children's academi c performance as well as in their social relationships. Whilethe teachers of children with special educational needs expect long-term academic performance advances from the children with Down syndrome, the teachers of children with typical development expect more immediate advances from them. The results indicate some similarities between the parents' and the teachers' beliefs; both groups understand that family support and involvement is crucial to the development of the children with Down syndrome.

KEYWORDS: Down syndrome; special education; values; beliefs; family.

${ }^{1}$ Este artigo foi baseado na tese de Doutorado, apresentada ao Instituto de Psicologia da Universidade de Brasília pela primeira autora, sob a orientação da segunda. As autoras agradecem o apoio concedido pelo CNPq.

${ }^{2}$ Doutora em Psicologia - Instituto de Psicologia - Universidade de Brasília - UnB; Instituto dePsicologia/ PED; Laboratório deDesenvolvimento Familiar; Campus Universitário Darcy Ribeiro; Brasília - liana@unb.br

${ }^{3}$ Professora Doutora do Instituto de Psicologia - Universidade de Brasília - UnB - dessen@unb.br 


\section{INTRODUÇÃo}

A família e a escola são duas instituições que exercem um papel de grande importância para o desenvolvimento do indivíduo. A família, vista como 'nicho ecológico' que proporciona sobrevivência e socialização às próximas gerações (KREPPNER, 2000) éa primeira mediadora entre o homem ea cultura, constituindo, assim, a unidade dinâmica das relações de cunho afetivo, social e cognitivo de um dado grupo social (POLONIA; DESSEN, 2005). A escola, por outro lado, também é um espaço de socialização e é o ambiente principal de transmissão do conhecimento sistematizado.

A família desempenha um papel tanto de impulsionadora como de inibidora dos processos de desenvolvimento do indivíduo, considerando as características do ambiente, bem como as relações familiares nele estabelecidas. Ela éa primeira mediadora entre o indi víduo e outros mi crossistemas e a cul tura, transmitindo os significados culturais para os membros de seu grupo ao longo de gerações. Essa transmissão se dá mediante as práticas educativas, as quais “... se concretizam em ações contínuas e habituais, nas trocas interpessoais" (SZYM AN SKI, 2000, p. 16), durante atividades rotineiras em que as crianças e seus genitores (ou outro cuidador) se engajam. Esse processo é denominado de 'proximal', de acordo com Bronfenbrenner (1999) e Bronfenbrenner e Morris (1998). Segundo esses autores,

para o desenvolvimento ocorrer, a pessoa deve estar envolvida em uma atividade que, por sua vez, deve acontecer regularmente e em períodos extensos de tempo, com uma duração suficientemente longa para se tornar crescentemente mais complexa (POLONIA; DESSEN; PEREIRA-SILVA, 2005, p. 83).

A escola também é um dos principais microssistemas promotores do desenvolvimento dos indivíduos. Trata-se da segunda instituição social de maior importância para as crianças pré-escolares e, em especial, para aquelas com deficiências, particularmente no quese refere à sua característica deestimuladora defunções cognitivas e sociais. A través da transmissão do conhecimento, a escola repassa seus valores, crenças e modos de comportar, os quais podem ou não entrar em conflito com os da família. Segundo Polonia e Dessen (2005), uma das tarefas mais importantes da escola é 'preparar' professores, pais e alunos para conviver com as dificuldades, em uma sociedade de mudanças rápidas, deforma a promover o desenvolvimento humano.

Tanto a escola como a família, têm o papel de preparar os indivíduos para a inserção destes na sociedade e para o desempenho de funções que possibilitem a continuidade da vida social (THIN , 2006). Estas duas instituições transmitem seus hábitos, valores ecrenças, especificam os papéis desempenhados no cotidiano e também ditam o modo de expressar os sentimentos. Contudo, há especificidades que são atribuídas à escola e outras que são responsabilidades da família. Por exemplo, a escola tem 
[...] a obrigação de ensinar (bem) conteúdos específicos de áreas do saber, escolhidos como sendo fundamentais para a instrução de novas gerações. $O$ problema de as crianças aprenderem fração é da escola. Família nenhuma tem essa obrigação. Por outro lado, professora alguma tem de dar "carinho maternal" para seus alunos. (SZYMANSKI, 2001, p. 62).

Devido ao grande número de configurações familiares é comum que cada família perceba a escola de acordo com suas concepções, fil losofias, valores ecrenças. Por exemplo, segundo Szymanski (2001), as famílias pobres acreditam quea escola podeajudar a sua criança no processo de desenvolvimento. Contudo, o diálogo que se estabelece entre estas famílias e a escola não facilita o alcance deste objetivo, uma vez que as famílias nem sempre têm os recursos para ajudar a criança e, a escola, por sua vez, não consegue oferecer possibilidades para as famílias. A pesar disso, os pais de crianças com dificuldades de aprendizagem atribuem à escola o poder de "dar o veredito sobre o futuro de seus filhos", conforme afirmam Borsotti e Braslavski (apud SZYM A N SKI, 2001, p. 71). Já no estudo de Macedo e Martins (2004), mães de crianças com síndrome de Down (SD), apesar de perceberem o despreparo dos professores para lidar com as demandas da escola inclusiva, destacam os avanços ocorridos no desenvolvimento dos filhos em decorrência de sua freqüência à escola.

Contudo, família eescola acabam tendo queaprender a conviver com as peculiaridades inerentes a cada ambiente e com os valores e as crenças transmitidos em ambos os microssistemas. A comunicação entre ambas deve ocorrer de forma harmoniosa, isto é, os val ores e as crenças devem ser similares, minimizando os possíveis conflitos entre as famílias e as escolas (SZYMANSKI, 2001). Os valores e as crenças parentais são construídos e exercem influência no desenvolvimento das crianças através de suas práticas (GOODN OW; COLLINS, 1990). Os genitores "agem com seus filhos em função de crenças desenvolvidas ao longo de suas vidas, através das vivências e experiências sociais e culturais" (MELCHIORI, 1999). Da mesma forma, também os professores agem com as crianças de acordo com seu conjunto de valores e crenças. Portanto, os valores e as crenças estão imersos na cultura e influenciam a construção do sistema de construtos eas práticas de cuidado eeducação de pais, mães, professores edemais cuidadores. Segundo McGillicuddy-DeLisi (1992), o ambiente de cuidado e socialização das crianças, criado através das estratégias usadas pelos cuidadores (genitores, professores etc.), tem um grande potencial de impacto no desenvolvimento social e pessoal da criança.

Assim, o objetivo deste artigo é apresentar os valores e crenças de genitores e de professores de crianças com e sem síndrome de Down. Os valores são entendidos como sendo os objetivos eas metas que os cuidadores (genitorese professores) almejam alcançar com as crianças; e as crenças são as idéias que eles têm sobre como ajudar as crianças a al cançarem os objetivos al mejados, isto é, os valores (LUSTER; RHOADES; HAAS, 1989). Pretendemos, neste estudo, responder às seguintes indagações: (1) há diferenças entre val ores e crenças dos 
genitores de crianças com síndrome de Down (SD) e com desenvolvimento típico (DT)? (2) como as professoras percebem as crianças com síndrome de Down e com desenvolvimento típico? $\mathrm{E}$, se há diferenças entre os valores e crenças das professoras em relação às crianças?

\section{M Étodo}

\section{Participantes}

Participaram desteestudo dez famílias compostas por mãe, pai efilhos. Em cinco famílias havia uma criança com síndrome de Down (SD) e, nas outras cinco, todas as crianças tinham desenvolvimento típico (DT) ${ }^{4}$. Todos os membros dafamília moravam juntos na cidade deBrasília $(n=10)$. A s crianças selecionadas para o estudo tinham entre dois a quatro anos de idade, no início da coleta de dados, sendo quatro do sexo masculino e seis do sexo feminino. Todas as crianças com síndrome de Down (SD) participavam do Programa de Estimulação Precoce da Secretaria de Estado de Educação do Distrito Federal . A s crianças tinham um tempo de freqüência no Programa que variava de 1 ano e 11 meses à 2 anos e 11 meses. Três crianças freqüentavam a escola de ensino regular no período contrário ao da Estimulação Precoce, tendo um tempo de freqüência de, aproximadamente, seis meses. Três crianças com desenvolvimento típico freqüentavam a pré-escola ou creche, enquanto que as demais ficavam em casa com as mães.

Nas famílias de crianças com SD, a idade das mães variou de 22 a 45 anos ( $M=36,4$ anos) e a dos pais de 24 a 54 anos ( $M=33,4$ anos); e nas famílias de crianças com DT, as mães tinham entre 30 e 35 anos ( $M=33,4$ anos) e os pais entre 29 e 38 anos ( $M=35$ anos). Quatro mães tinham completado o ensino médio (SD: $n=1 ; \mathrm{DT}: \mathrm{n}=3$ ), três delas tinham o ensino fundamental incompleto (SD: $n=2$; DT: $n=1$ ) e três o ensino superior completo (SD: $n=2 ; \mathrm{DT}: n=1$ ). Quanto aos pais, a maioria tinha o ensino superior completo ou incompleto (SD: $n=3$; DT: $n=2$ ), três tinham o ensino médio completo ou incompleto (DT: $n=3$ ), dois deles tinham o ensino fundamental completo ou incompleto (SD: $n=2$ ). A maioria dos pais ( $n=8$ ) estava trabal hando, um era aposentado e outro estava desempregado. A metade das mães trabal hava fora de casa (SD: $n=3 ; \mathrm{DT}: n=2$ ) enquanto a outra metade não trabal hava fora (DT: $n=3 ; S D: n=2)$. A renda familiar média era de 7,2 salários mínimos, por ocasião da coleta de dados.

Foram entrevistadas 10 professoras, sendo três do ensino especial e sete do ensino regular; destas últimas, quatro eram professoras das crianças com DT etrês das crianças com SD que estavam freqüentando o ensino regular. Uma professora foi entrevistada duas vezes, pois dois de seus alunos (SD) participavam do estudo, totalizando 11 entrevistas com as professoras. M etade das professoras

\footnotetext{
${ }^{4}$ Crianças que apresentam características típicas do ponto de vista do desenvolvimento humano, ou seja, não são diagnosticadas, rotuladas ou classificadas por profissionais da área de saúde como apresentando algum tipo de anomalia ou doença, seja física, mental ou psicológica.
} 
$(n=5)$ tinha acima de 35 anos de idade e a outra metade $(n=5)$ tinha entre 18 e 29 anos. Cinco professoras cursaram o ensino médio (magistério), quatro concluíram o curso superior e uma estava cursando o ensino superior. Todas as professoras do ensino especial $(n=3)$ tinham freqüentado cursos de especialização nesta área. Quanto ao tempo de serviço no magistério, a maioria $(n=8)$ possuía de um a onze anos e duas tinham mais de 17 anos de trabal ho.

\section{Procedimentos}

A coleta de dados com as dez famílias foi efetuada somente pela pesquisadora, na própria residência das mesmas. Para a coleta de dados, foram efetuadas visitas semestrais às famílias; na primeira delas, os genitores assi naram o Termo de Consentimento Livre e Esclarecido e responderam às questões constantes do questionário sóciodemográfico da família (DESSEN, 1999). O objetivo deste questionário era obter dados demográficos da família, bem como dos contatos sociais, das atividades rotineiras e de lazer do grupo familiar. $\mathrm{Na}$ visita seguinte, foram realizadas entrevistas semi-estruturadas conduzidas com pais e mães, separadamente, consistindo na obtenção de dados sobre a história de vida da criança, o diagnóstico, os hábitos eos costumes da criança eda família, as características comportamentais e emocionais da criança e os valores, crenças e expectativas dos genitores em relação ao filho/ filha. A duração da entrevista com as mães foi de, aproximadamente, 45 minutos e com os pais 30 minutos.

Com relação às professoras, foi realizada uma única visita a cada uma delas, no local de trabalho, em dia e horário estabelecidos por elas. As entrevistas consistiram na obtenção de informações a respeito do relacionamento da criança com os companhei ros, bem como da percepção das professoras sobre o desempenho da criança na escola, seus relacionamentos na família e os valores e crenças que elas tinham em relação ao futuro das crianças. Esta entrevista teve duração de, aproximadamente, 30 minutos. Os roteiros de entrevista, dos genitores e professoras, foram construídos para a coleta de dados de tese de doutorado (PEREIRA-SILVA, 2003), sendo que o presente artigo focaliza apenas os dados relativos aos valores, crenças e expectativas dos genitores e professoras.

Todas as entrevistas foram gravadas etranscritas naíntegra, seguindo a seqüência do roteiro preestabelecido, com o objetivo de identificar os aspectos relevantes em cada questão, visando à construção do sistema de categorias. Para a análise dos val ores e crenças dos genitores, os dados foram agrupados, considerando os seguintes temas: (1) Desenvolvimento motor; (2) Escolarização; (3) Profissionalização e (4) Relacionamentos íntimos. Os relatos das entrevistas com as professoras foram subdivididos em cinco temas: (1) Descrição do desempenho da criança na escola/ estimulação precoce; (2) Relacionamentos da criança, dentro e fora da sala de aula, com a própria professora e com os companheiros; (3) Relacionamentos da criança com sua família; (4) Mudanças ocorridas com a criança desde que começou a freqüentar a escola; (5) Expectativas da professora 
em relação à criança. As categorias elaboradas para cada um dos temas mencionados acima não são mutuamente exclusivas, isto é, um genitor ou professor pode ter relatado mais de uma categoria.

\section{Resultados}

V aLores E CRENÇAS dos GeNitores de CRIANÇAS COM SD E COM DT

A respeito do 'desenvolvimento motor' do filho, verificou-sequeapenas os genitores das crianças com síndrome de Down relataram valores e crenças relacionados a este aspecto. A maioria deles relatou que ‘Desenvolver melhor' ( $n$ $=7$ ) as habilidades motoras é o que eles almejam para seus filhos. Dentre este total, quatro mães esperavam que seu filho/ filha ‘Desenvolvessemel hor algumas habilidades específicas', como se verifica pelo relato abaixo:

“Eu espero assim [...] não é o que eu anseio, assim... eu acho que L. vai fazer muito bem um tipo de esporte; dançar balé, eu não curto muito balé, não, sabe? Mas eu acho que ela leva um jeitinho pra isso aí" (mãe)

[...] “Que jogue bola, que ande de bicicl eta, que faça natação, que consiga..., é claro, quenão quero que seja um maratonista, queseja um jogador de futebol famoso, nada disso, mas que tenha a desenvoltura normal, as habilidades normais, coordenação motora normal pra que seja independente [...]" (pai)

Três desses genitores não especificaram quais habilidades esperam que seu filho/ filha desenvolva, embora tenham relatado o desejo de que eles 'Desenvolvam habilidades globais', conforme exemplificado a seguir:

\section{[...]“Ah, sei lá! Eu espero que ela desenvolva bem” (pai)}

“Olha, a gente tenta sempre enxergar lá na frente, né? Mas a gente tá vivendo muito o agora mesmo, vamos acompanhando, tentando ter um desenvolvimento motor normal, agora, a expectativa é que ele tenha um desenvolvimento normal mesmo [...]" (mãe)

A penas uma mãe relatou que esperava que seu filho 'Al cançasse seu limite' $(n=1)$, isto é, que ele superasse as dificuldades motoras impostas pela própria síndrome de Down. A crença no 'Esforço dos genitores' para que a criança com SD alcançasse os objetivos esperados foi relatada pela maioria dos pais e mães $(n=4)$.

[...]“Porquenós estamos propiciando, tentando propiciar pra el a uma estrutura que, cuja única perspectiva, vai ser essa: uma pessoa bem realizada, uma pessoa tranqüila, uma pessoa independente [...]" .

Dois genitores tinham a crença de que se o filho/ filha ‘Fizessealguma atividade física' $(n=1)$ e 'Freqüentasse o ensino regular' $(n=1)$ poderia al cançar os valores desejados para o desenvolvimento motor da criança com SD. Por outro lado, quatro genitores mencionaram a inexistência de crenças a respeito do desenvolvimento motor do filho/ filha ('A usência de crenças' - $n=4$ ). 
A respeito do tema 'Escolarização', as seguintes categorias foram mencionadas pelos genitores de crianças com SD e DT: 'Completar a escolarização' ( $n=9$ ), isto é, terminar o ensino fundamental el ou o médio ou, então, o ensino superior e/ ou profissionalizante; 'A prender noções básicas da vida' ( $n=2$ ) através da escolarização; 'Respeito ao limite da criança' ( $n=2)$, isto é, tolerância às capacidades física, mental e do desenvolvimento da criança. Somente os genitores de crianças com SD esperavam que seus filhos tivessem 'M elhoria no desenvolvimento' $(n=2)$ deforma global ena 'Social ização' $(n=1)$. A Figura 1 mostra os valores associados à escolarização, segundo pais e mães.

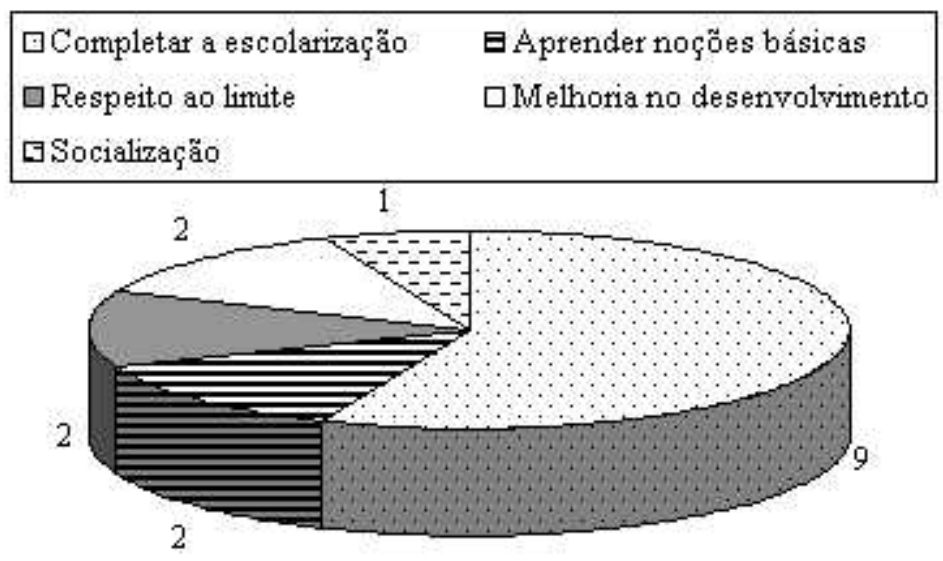

Figura 1 - Valores dos genitores quanto à ‘Escolarização’. As categorias não são mutuamente exclusivas.

Para alcançar os valores relacionados à escolarização, os genitores tinham crenças relativas ao esforço deles próprios ('Esforço dos genitores': $n=9$ ) para propiciar ao filho os ganhos acadêmicos. Mas, eles também acreditavam no 'Incentivo/ estímulo à criança' ( $n=3$ ) para continuar os estudos, na 'Capacidade da criança' ( $n=2)$ e em seu potencial para se dedicar ao estudo ('Muito estudo': $n=1)$. Em se tratando de crianças com SD, os genitores $(n=3)$ acreditavam que ao freqüentar a escola regular, seu filho(a) se tornaria igual às demais crianças com desenvolvimento típico. Por exemplo,

"Acredito que ela vai sim, conseguir ser igual às outras crianças, normal" (pai)

“[...] N ormal igual às outras crianças, acho que vai ser igual” (mãe)

Quanto à 'profissionalização', a maioria dos genitores esperava que seus filhos 'Tivessem uma profissão' ( $n=15)$; destes, apenas quatro 'Identificaram as profissões' esperadas: Advogado ou qualquer outra profissão na área jurídica $(S D: n=1$; DT: $n=2$ ) e Artista (DT: $n=1$ ). Foi relatado também por um pai de 
criança com SD o desejo de o(a) filho/ filha ter um 'Bom emprego'. As crenças relacionadas à profissionalização não foram mencionadas pela maioria dos genitores $(n=13)$. No entanto, alguns genitores acreditavam que 'Montando uma micro-empresa/ negócio próprio' para o(a) filho/ filha $(n=3)$, ele poderia chegar à profissionalização; outros genitores acreditavam que seus filhos conseguiriam ter uma profissão 'A través do estudo' $(n=3)$ ou por meio de 'Estímulo à criança' ( $n=1)$.

Quanto aos valores associados ao tema 'relacionamentos íntimos', a maioria dos genitores $(n=10)$ esperava que seus filhos 'Cumprissem as etapas naturais do ciclo de vida', no que se referia aos relacionamentos sociais, ou seja, namorar, casar e ter filhos. Segundo os genitores, seus filhos poderiam al cançar 'Todas' ( $n=7$ ) essas etapas ou, apenas, 'Algumas delas' $(n=3)$. Em se tratando de genitores de crianças com SD, eles relataram que 'Respeitariam o limite/ desenvolvimento da criança' $(n=3)$ e que estas poderiam ' $N$ ão cumprir as etapas' do ciclo vital $(n=2)$. A Figura 2 apresenta os val ores relatados pel os genitores no que se refere aos relacionamentos íntimos dos filhos.

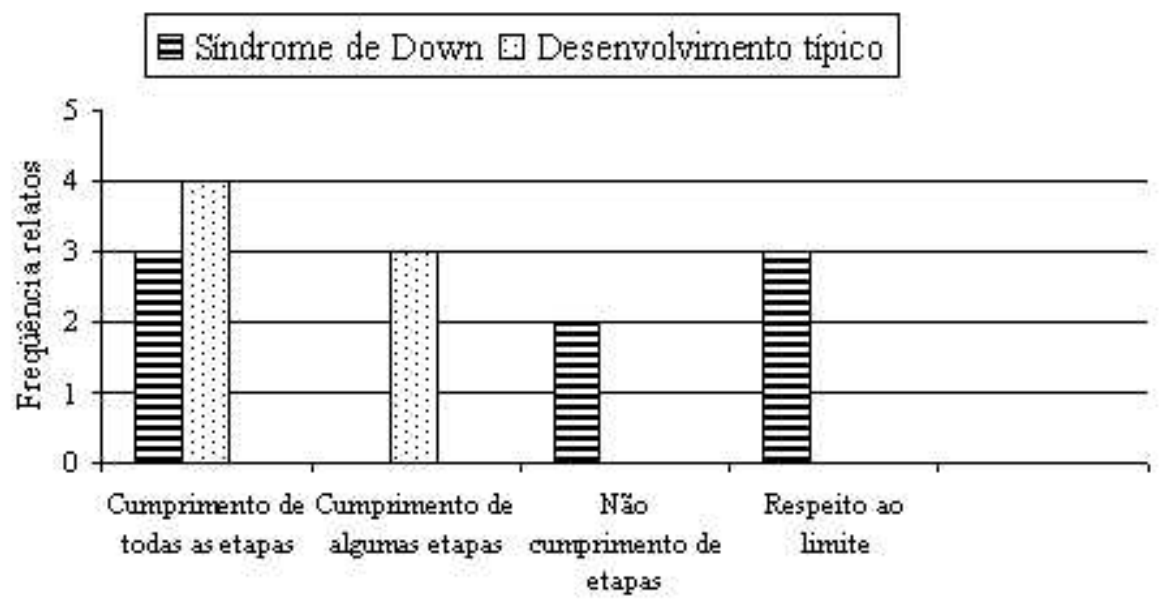

Figura 2 - Valores dos genitores quanto aos relacionamentos íntimos, por tipo de família. As categorias não são mutuamente exclusivas.

A maioria dos genitores $(n=11)$ não relatou suas crenças a respeito de como al cançar os valores sobre relacionamentos íntimos esperados para seus filhos. No entanto, al guns deles acreditavam que poderiam al cançar os objetivos almejados por meio de 'Orientação fornecida por eles aos filhos' $(n=3)$ ou por 'Imposição de limites' à criança $(n=2)$.

Os genitores das crianças com DT relataram uma diversidade de valores relacionados ao tema 'Expectativas quanto ao futuro' de seus filhos: 'Ter saúdefísica', 'Felicidadee realização', 'Ser uma pessoa trabal hadora/ batalhadora' e 'Ser uma pessoa segura'. 
[...]“Q Quero que ele seja feliz, que tenha saúde, que cure dessa asma, isso me preocupa muito porque tol he muito esse lado dele de querer ser esportista [...]" (mãe).

"[...] Gostaria de um dia ver o meu filho bem, sendo al guma coisa ou fazendo al guma coisa que ele gostasse, não precisava ser um médico, um doutor, al guma coisa queele gostasse, que eu acho que a partir do momento que você faz uma coisa que você gosta, seja qualquer profissão, você tá feliz assim, assim eu acho que a gente tá realizado [...]" (mãe).

“[...] Eu queria assim, que el es conseguissem é [...] chegar lá e conseguir ser como eu, como o R. [o pai] é ... batal hadores [...]" (mãe)

"[...] eu quero dizer que ele possa se virar sozinho, enfrentar o mundo aí fora, saber encarar as coisas de uma maneira serena, uma maneira clara, sem muito [...] sem muita dúvida [...]" (pai)

A penas os genitores de crianças com SD relataram a preocupação com a'Independência financeira' de seus filhos ea 'A ceitação social'. Por exemplo,

[...] “Em termos de salário, de convivência com os colegas, eu torço pra que ele, real mente, possa é[...] quando crescer ter esselugar, sed efender, né? Não precisar depender de família o resto da vida. Que seja independente"

"A cho que a minha expectativa é a de todos os pais que têm crianças com deficiências, é de aceitação perante a sociedade, porque ainda existe muita é [...] como é que fala? Preconceito, ainda existe muito preconceito" (mãe).

Os genitores deste estudo acreditavam nas seguintes estratégias para al cançar os valores quanto ao futuro de seus filhos: 'Propiciar condições à criança de ser independente' (SD: $n=1$ ), 'Fazer aquilo que [a criança] gosta' (SD: $n=1$ ), 'Terminar a escolarização' (DT: $n=1$ ), seguir a 'Orientação dos genitores' (DT:n $=1)$, 'Transmitir ensinamentos, val ores eexperiência de vida dos pais' (DT:n =1) e 'Seguir o ensinamento dos pais' (DT: $n=1$ ). Além disso, um genitor acreditava que uma das estratégias apropriadas seria a 'Não discriminação' (SD: $n=1$ ) do filho, por parte da sociedade.

Quatro genitores de crianças com DT definiram seus valores quanto ao futuro do filho, em função de suas crenças pessoais de que o futuro ‘só à Deus pertence'.

[...] “Tem que entregar muito na mão de Deus, só Ele sabe o futuro, né? [...]".

[...]" Olha, o futuro deuma criança, acho queos pais tem quepedir a Deus, né, muita ajuda [...]".

\section{Como as professoras percebem as crianças?}

Sobre o desempenho das crianças, as professoras do ensino regular $(n=7)$, tanto das crianças com SD como das crianças com DT, e as do ensino especial $(n=4)$ relataram que as crianças tiveram um desempenho satisfatório na escola e/ ou na estimulação precoce desde que iniciaram a escolarização. 
Segundo o relato das professoras do ensino especial, as crianças com síndromedeDown apresentaram mel horia no desenvolvimento neuropsicomotor $(n=4)$, na linguagem $(n=2)$ e na socialização $(n=1)$, tendo adquirido uma maior independência nas atividades de vida diária $(n=1)$. As professoras de ensino regular das crianças com SD relataram que estas crianças tiveram uma melhoria na coordenação motora $(n=3)$, na linguagem $(n=2)$, na participação em sala de aula $(n=1)$ e nos relacionamentos com os colegas $(n=1)$. A s crianças com DT, por sua vez, melhoraram a concentração e atenção $(n=2)$, 0 desenvolvimento psicomotor $(n=2)$ e a apreensão do conteúdo básico para alfabetização $(n=1)$.

A maioria das professoras considerou 'A mistoso' o seu relacionamento com as crianças ( $n=11)$, e destas com os col egas de sala $(n=9)$ e com os membros da família $(n=11)$. A penas uma criança foi percebida como apresentando um relacionamento com seus colegas ora amistoso ora conflituoso ( $n=1)$; e outra apenas 'Conflituoso' ( $n=1)$.

“Olha, éa mesma coisa que eu observo nos outros. Se relaciona bem, é uma criança calma, carinhosa, mas, assim, se deixar ele fica brincando mais com ele mesmo" (professora de criança com SD)

“Com os col eguinhas, há umas dificul dades com al guns, né? Porque depende também de personalidade, uns não gostam dos outros. Às vezes, não gosta dele, mas isso é normal dentro da sala de aula, é normal [...]" (professora de criança com SD).

“É amigo de todo mundo. Ele nunca briga, ele não bate, ele vai apaziguar a sala quando estão brigando" (professora de criança com DT).

As professoras relataram valores diferentes para crianças com síndrome de Down e com desenvolvimento típico, o que significa que elas têm expectativas diferenciadas para ambos os tipos de crianças. Quanto ao desempenho das crianças com SD, as professoras do ensino especial almejam: 'Melhoria no desenvolvimento' $(n=2)$, 'Independência em atividades de vida diária' ( $n=1)$ e 'Inclusão da criança no ensino regular' $(n=1)$, como mostra os relatos a seguir:

"Eu acredito que ela vá continuar crescendo, porque ela é muito espertinha, sabe, acho que ela vai continuar desenvolvendo bem [...]

[...] “A cho que ela tem condições sim detá acompanhando o jardim I, acredito que ela vá conseguir sim seguir junto com a turma regular, a pré-escola...

Já as professoras das crianças com SD incluídas no ensino regular não souberam definir as suas expectativas com relação à criança ('Indefinição de valores': $n=2$ ) e apenas uma espera que a criança 'Seja alfabetizada'.

“As melhores possíveis porque, pelo que eu já li, pelo que... experiência mesmo éa primeira criança que eu trabal ho quetem síndromedeDown, mas já li muito [...], mas as minhas expectativas são as mel hores possíveis". 
[...] "O meu desempenho com a L., eu tenho me esforçado ao máximo pra deixar ela pronta até o final do ano, pra... a partir do ano que vem, ela ter condição boa de não ficar pra trás, né, pra alfabetização, pra começar a partir de agosto já ver se engrena e vai direitinho".

Em se tratando das ações das professoras para alcançar os valores almejados (crenças), as professoras de crianças com SD, tanto as do ensino especial como as do ensino regular relataram: 'O investimento da família' $(n=2)$, 'Persistência e respeito ao ritmo da criança' $(n=1)$, 'A companhamento especializado' ( $n=1)$ e 'Investimento da professora' $(n=1)$. Exemplos,

“[...]. Pelo investimento da família nisso e pel os conhecimentos dele, el e vai se dar bem, num ritmo dele, sempre eu lembro disso [...]".

“[...] A minha expectativa, pelo conhecimento das outras crianças, éessa, que ele tem condições, mas tem que ter paciência e respeitar o ritmo dele, sabe [...]".

Quanto ao desempenho das crianças com DT, as professoras esperam que eles possam: 'Alcançar maior maturidade' $(n=1)$, 'A prender o conteúdo básico do curso que freqüenta' $(n=3)$, 'M el horar a coordenação motora' $(n=1)$ e ‘Concluir da escolarização' ( $n=1)$. Por exemplo,

[...] “Que ela alcance mais maturidade, mais concentração pra realização das tarefas e na parte do cognitivo, o que a criança precisa, né, no final do ano, isso é o básico, conhecer números, letras, as cores, figuras geométricas e pra ela vai ser muito tranqüilo [...]".

[...] “Então eu espero que quando chegar assim, setembro, outubro, que já tenhaterminado todas as consoantes equeel es consigam ler palavras dissílabas [...]"

Quanto às estratégias para se alcançar os objetivos citados pelas professoras, foram destacadas a 'Confiança no trabalho da escola/ professora' (n =2) e a importância do 'Trabalho da família' junto ao aluno $(n=2)$. Exemplos:

[...] “O método que a gente trabalha, um dos pontos que a gente fixa muito é saber esperar a sua vez, ésaber respeitar o espaço do outro, né? A cho que isso contribui bastante".

“Bom, o G. por ele ser tão responsável etambém pelo pou co que eu conheço da mãe, porque eu não conheço o pai, eu conheço o pai só quando ele vem buscar, parece uma pessoa muito equilibrada, concentrada, responsável, pelo jeito delee o menino éa cópia, porque os pais são a estrutura da família, né?"

Quanto ao futuro das crianças com SD, as professoras do ensino especial esperam que a 'Sociedade tenha mais respeito pelas crianças com deficiências' ( $n=1)$, eque as crianças sejam 'Independentes em atividades de vida diária' $(n=1)$, quetenham mais 'Liberdade' $(n=1)$, que'Melhorem seu desempenho escolar' $(n=1)$ eque consigam 'Entrar no mercado de trabal ho' $(n=1)$. Exemplos: 
[...] “'A questão social..., isso é Brasil, né? E a genteespera queocorram algumas mudanças, sabe, as pessoas passem a respeitar, porque, na realidade, diz-se que há respeito, não sei o que, mas eu não vejo, na prática, pra mim, essas coisas não funcionam, então essa questão de futuro é preocupante...".

[...] “Eu acredito que el es vão gradual mente melhorando, aprendendo a ficar mais independentes nas atividades devida diária, né, na partedo desempenho escolar, na parte de leitura, isso aí tem que ter bastante persistência...".

Já as professoras das crianças com SD do ensino regular esperam que estas 'A tinjam o seu limite', independente do tempo $(n=1)$, que sejam 'A I guém na vida' $(n=1)$, que haja 'Melhoria no desenvolvimento da criança' $(n=1)$, que a mesma 'Seja uma boa aluna' $(n=1)$ e que a criança esteja 'Preparada para enfrentar o mundo' $(n=1)$. Exemplos:

[...]“Elevai chegar ao ápice, assim quetiver todo mundo estimulando, fazendo por ele, ele chega sim. Só que tem que haver uma independência de tempo, porque o tempo dele é ele que faz, não a gente".

[...] "Que ela saia, se ela continuar aqui na S. (nome da escola), que ela saia preparada pro mundo, né? que é uma das coisas que eu tento fazer muito ..."

As professoras acreditavam que o 'Investimento, estímulo eapoio da família e profissionais' $(n=4)$, os 'A companhamentos especializados' $(n=1)$ e os 'Ensinamentos transmitidos pela escola' $(n=1)$ seriam as estratégias para propiciar o alcance dos valores mencionados por elas quanto ao futuro das crianças com SD.

Quanto ao futuro das crianças com DT, as professoras esperam que elas 'Completem a escolarização' $(n=2)$, 'Tenham um bom desempenho em qualquer atividade que desenvolver' $(n=1)$ e que 'Alcancem uma maior capacidade de concentração' $(n=1)$. Exemplos:

[...] "A cho quea B., o queela fizer, ela vai sedar muito bem, porque ela, assim ... ela tem uma alegria muito grande; el a tem facilidade em se comunicar, de cativar as pessoas, ela procura as coisas que ela quer, que é do interesse dela ....".

[...] “Que el ese desenvolva, que el e consiga administrar essa agitação queele tem, essa ansiedade que ele tem [...], assim, essa concentração mesmo que ele vai precisar ter...".

Segundo as professoras, as estratégias para se alcançar os objetivos acima citados ‘Dependem das características pessoais da criança' $(n=2)$ e do 'A poio da família' ( $n=1)$. Por exemplo,

[...] "Ela tem uma al egria muito grande, né? Ela tem facilidade em se comunicar, de cativar as pessoas, el a procura as coisas que ela quer, que édo interesse dela, ela procura alcançar os objetivos, sabe?"

[...] “Ela não éuma criança que você chama a atenção e el a fica triste; ela pensa logo e dá a volta por cima, sabe? Então eu acho que el a tem uma força muito grande, né? E o apoio da família que é muito importante". 


\section{DIscussão}

Os valores mencionados pelos genitores decrianças com SD diferiram dos valores dos genitores de crianças com DT, especificamente no que se refere ao desenvolvimento motor e ao futuro da criança. $\mathrm{N}$ as famílias de crianças com DT não foram citados valores referentes ao desenvolvimento motor do filho, provavelmente, pelo fato de os genitores estarem satisfeitos com o desempenho demonstrado pela criança ou pel o não reconhecimento dealgum déficit ou falha no seu desenvolvimento motor. A preocupação com o desenvolvimento motor da criança com síndrome de Down está relacionada à preocupação com o futuro deste, pois seas dificuldades motoras não forem superadas, provavel mente, mais adiante, as barreiras poderão ser maiores.

No estudo de Glat e Duque (2003), os pais de pessoas com necessidades educacionais especiais (NEE) também rel ataram preocupação com o desenvolvimento dos filhos, especialmente, nas áreas de leitura, escrita, linguagem oral edesenvolvimento cognitivo. Déficits em tais áreas podem impedir uma adaptação da criança ao ambiente em que vive, tornando-se, assim, um dos pontos centrais de preocupação dos pais em relação ao futuro de seus filhos. Quanto ao futuro das crianças, os val ores dos genitores nas famílias de crianças com DT foram mais relacionados à realização e felicidade da criança do que à sua independência e aceitação social, como se verificou em famílias de crianças com SD. Esses valores, eas crenças associadas a eles, refletem a preocupação dos genitores face às conseqüências provocadas pela síndrome de Down, o que também foi constatado por Macedo e Martins (2004).

Um outro tipo de preocupação, freqüentemente relatada por mães e pais decrianças com deficiência, ésobrea sexualidade dos filhos. Em nosso estudo, essa preocupação pôde ser abstraída dos valores e crenças relatados pelos genitores das crianças com SD, no que se refere aos seus relacionamentos íntimos. Segundo Wong (2002), as crenças comuns associadas à sexualidade de pessoas com síndrome de Down são as de que essas pessoas (a) são 'assexuadas', isto é, não possuem vida sexual ou, ao contrário, de que (b) elas não têm controle sobre sua própria sexualidade; (c) são pessoas mais propensas a terem filhos com deficiência mental, por isso deve-se esterilizá-las; (d) elas devem relacionar-se com pessoas iguais a elas, isto é, com alguma deficiência mental; e (e) são exclusivamente heterossexuais. Algumas destas crenças datam do século XIX; contudo, no relato de alguns genitores de nosso estudo, ainda verificamos a existência de parte delas.

Essas crenças podem impedir que as pessoas com síndrome de Down tenham um desenvolvimento emocional e sexual saudável, uma vez que o modo de agir dos genitores poderá estar impregnado de práticas discriminatórias. A sexualidade também foi uma preocupação mencionada pelos pais no estudo de Glate Duque (2003). Segundo estas autoras, a família e os profissionais enxergam a sexualidade das pessoas com NEE como se fosse al go patológico. Assim, família 
eprofissionais, especial mente professores, ainda não estão preparados para lidar com as manifestações sexuais das pessoas com NEE, surpreendendo-se ao se depararem com essas experiências (MAIA; ARANHA, 2005).

Com relação ao desempenho das crianças com SD na escola, tanto as professoras do ensino especial quanto aquelas do ensino regular emitiram opiniões similares sobre o desempenho 'satisfatório' das crianças com SD. No entanto, algumas diferenças entre os valores das professoras das crianças com SD e daquel as de crianças com DT foram constatadas, no que se refere ao futuro de tais crianças. As primeiras relataram expectativas relativas não somente ao desenvolvimento cognitivo, motor e social da criança, mas também quanto à mel horia nas formas de tratar a pessoa com deficiência, por parte da sociedade. Já, as outras professoras, relataram mais freqüentemente valores relacionados ao desenvolvimento cognitivo das crianças com DT. Além disso, as professoras das crianças com SD do ensino regular esperam resultados em longo prazo, enquanto as de crianças com DT esperam resultados mais imediatos. Estas expectativas parecem ser decorrentes da percepção apropriada das professoras em relação à competência cognitiva e social de ambas as crianças.

Em geral, as crianças com SD de nosso estudo conviviam bem com seus colegas sem deficiências e com as professoras, o que foi comprovado por al guns estudos queanalisaram as interações entre companheiros, tendo um deles deficiência (ARA NHA, 1991; BATISTA; ENUM O, 2004) e interações professoraluno com deficiência (CERQUEI RA-SILVA; ARAN HA, 2005). PottieeSumarah (2004), investigando a relação interpessoal ea amizade entre pessoas com e sem deficiências, afirmaram que os amigos sem deficiências acabam desempenhando o papel decuidadores daqueles com deficiência. Porém, segundo esses autores, a amizade entre eles vai além desta função, havendo o reconhecimento de que a pessoa com deficiência tem algo a mais para dar em troca, sendo a relação caracterizada por uma mutualidade e interdependência entre os parceiros. Embora tenhamos investigado a interação entre crianças com SD e com DT no ambiente escolar somente por meio de entrevistas com as professoras e não por meio de técnicas de observação, os dados sugerem que estas crianças estão se beneficiando do processo de inclusão, especialmente, no que diz respeito à socialização.

No entanto, é preocupante o fato de que alguns dos genitores de crianças com SD acreditem que, com a freqüência à escola regular, seus filhos poderão vir a se tornar crianças com desenvolvimento típico, sobretudo no que concerne ao aspecto cognitivo. Sugerimos, portanto, que as políticas públicas e os programas deorientação a pais de crianças com deficiência enfatizem a etiologia da deficiência como um dos recursos para conscientização dos objetivos da inclusão escolar destes alunos. Pereira-Silva e Dessen $(2004,2005)$ discutem a necessidade de os programas de educação familiar ser elaborados tendo como arcabouço uma baseempírica. Ter uma baseempírica significa incluir não somente 
os profissionais, mas também os professores e a família das pessoas com NEE como fontes de informação para a construção dos programas. Assim, possuir uma base empírica e prever avaliações sistemáticas são dois requisitos básicos para garantir a eficácia de tais programas.

Em nosso estudo, ficou evidenciado queas professoras consideravam a família como sendo a fonte principal de apoio às crianças com SD. As professoras das crianças com SD que estavam no ensino regular acreditavam que o trabalho da família era mais efetivo do que o seu trabalho, enquanto as professoras de crianças com DT acreditavam mais na eficácia de seu próprio trabal ho com a criança. Provavelmente, a percepção das professoras de crianças com SD seja decorrente do 'medo de fracassar' e, conseqüentemente, elas atribuem à família a maior responsabilidade pela criança. Talvez, elas reconhecessem a sua falta de preparação para lidar com crianças com deficiência, uma vez que nenhuma relatou ter tido experiência prévia com crianças com NEE ou ter freqüentado algum curso, realidade encontrada também por Gomes e Barbosa (2006). Para Sant'A na (2005), a fal ta de preparo do professor, tem setornado um dos obstáculos à inclusão, apesar de professores e diretores de escolas serem favoráveis e receptíveis à inclusão de crianças com NEE. Mas, independente disto, a inclusão é um processo inevitável, com escolas, professores, famílias e comunidade vivenciando esse processo no seu dia-a-dia (AIELLO, 2002; MATISKEI, 2004).

A tendência decolocar na família a maior responsabilidade pelo curso de desenvolvimento da criança pode ser verificada em vários outros aspectos investigados em nosso estudo, sobretudo no que tange à escolarização. Por exemplo, pais e professoras mencionaram que uma escolarização bem sucedida 'depende do esforço, do estímulo e do apoio da família', o que enfatiza a idéia de uma participação mais efetiva da família no processo de desenvolvimento e escolarização de crianças com deficiência. Portanto, as professoras precisam ser incentivadas a reconhecer a eficácia de seu próprio trabal ho com as crianças.

Família e escola possuem papéis distintos e complementares, como tem sido enfatizado pela literatura (POLONIA; DESSEN, 2005; SZYMANSKI, 2000, 2001; THIN , 2006). Não resta dúvida que a escola e a família constituem ambientes de promoção do desenvol vimento humano e, em especial, de crianças com deficiências. E quando há uma continuidade entre os valores e as crenças entre a família e a escola, a aprendizagem se torna mais efetiva, significativa e propulsora do desenvolvimento da criança (SILVERN , 1988). A creditamos quea implementação de políticas visando à integração família-escola deve considerar as diferenças entre os contextos familiar e escolar, definindo, com clareza, as funções de cada um. Definir com clareza e objetividade dessas funções constitui um dos grandes desafios, considerando que ambos os microssistemas estão em constante transformação, em uma sociedade também em desenvolvimento (POLONIA; DESSEN, 2005). 


\section{ReferênCIAS}

AIELLO, A.L.R. Família inclusiva. In: PALHARES, M.S., MARINS, S. (Org.). Escola inclusiva. São Carlos: EdUFSCar, 2002.

ARANHA, M.S.F. A interação social e o desenvolvimento de relações interpessoais do deficiente em ambiente integrado. 1991. $145 \mathrm{f}$. Tese (Doutorado em Psicologia Experimental) - Instituto de Psicologia, Universidade de São Paulo, São Paulo.

BATISTA, M.W.; ENUMO, S.R.F. Inclusão escolar e deficiência mental: análise da interação social entre companheiros. Estudos de Psicologia, Natal, v. 9, n. 1, p. 101-111, 2004.

BRONFENBREN NER, U. Environments in developmental perspective: Theoretical and operational models. In: FRIEDMAN, S.L., WACHS, T.D. (Org.). M easuring environment across the life span: emerging methods and concepts. Washington, DC: American Psychological Association, 1999.

BRONFENBREN NER, U.; MORRIS, P.A. The ecology of developmental processes. In: DAMON, W.; LERNER, R.M. (Org.). H andbook of child psychology: Vol. 1: theoretical models of human development. New York: Wiley, 1998.

CERQUEIRA-SILVA, S.; ARANHA, M.S.F. Interação entre professora e alunos em sala de aulas com proposta pedagógica de educação inclusiva. R evista Brasileira deE ducação Especial, Marília, v. 11, n. 3, p. 373-394, 2005.

DESSEN, M.A. Questionário sócio-demográfico da família. Manuscrito não publicado, Laboratório de Desenvol vimento Familiar, Instituto dePsicologia da UniversidadedeBrasília, Brasília, 1999.

GLAT, R.; DUQUE, M.A.T. Conviven do com filhos especiais: o olhar paterno. Rio de Janeiro: Viveiros de Castro Editora Ltda, 2003.

GOMES, C.; BARBOSA, A. Inclusão escolar do portador de paralisia cerebral: atitudes de professores do ensino fundamental. R evista Brasileira deE ducação Especial , M arília, v. 22, n. 1, p. 85-100, 2006.

GOODNOW, J.J.; COLLINS, W.A. D evelopment according to parents: the nature, sources, and consequences of parents' ideas. Hillsdale, NJ: Lawrence Erlbaum, 1990.

KREPPNER, K. The child and the family: interdependence in developmental pathways. Psicologia: Teoria e Pesquisa, Brasília, v. 16, n. 1, p. 11-22, 2000.

LUSTER, T.; RHOADES, K.; HAAS, B. The relation between parental values and parenting behavior: a test of the Kohn hypothesis. Journal of M arriage and the Family, v. 51, p. 139-147, 1989.

MACEDO, B.C.; M ARTINS, L.A.R. Visão de mães sobre o processo educativo dos filhos com síndromedeDown. Educar em Revista, Curitiba, n. 23, p. 143-159, 2004. 
MAIA, A .C.B.; ARA NHA, M.S.F. Relatos deprofessores sobremanifestações sexuais dealunos com deficiência no contexto escolar. Interação em Psicologia, Curitiba, v. 9, n. 1, p. 103-116, 2005.

MATISKEI, A.C.R.M. Políticas públicas de inclusão educacional: desafios e perspectivas. Educar em Revista, Curitiba, n. 23, p. 185-202, 2004.

MCGILLICUDDY-DELISI, A.V. Parents' beliefs and chidren's personal-social development. In: SIGEL, I.E.; M CGILLICUDDY-DELISI, A.V.; GOODN OW; J.J. (Org.). Parental belief systems: the psychological consequences for children. Hillsdale, NJ: Lawrence Erlbaum, 1992.

MELCHIORI, L.E. D esenvol vimento e comportamento de bebês (de 0 a 2 anos) na rotina, segundo a visão das educadoras deambiente col etivo. 1999. 218f. Tese (Doutorado em Psicologia) - Faculdade deFilosofia, Ciências e Letras de Ribeirão Preto, Universidade deSão Paulo, Ribeirão Preto, 1999.

PEREIRA-SILVA, N.L. Famílias decrianças com esem síndromede D own:umestudo comparativos das relações familiares. 2003. 263f. Tese(Doutorado em Psicologia) - Instituto de Psicologia, Universidade de Brasília, Brasília, 2003.

PEREIRA-SILVA, N.L.; DESSEN, M .A . A família e os programas de intervenção: tendências atuais. In: MENDES, E.G.; ALMEIDA, M.A.; WILLIAMS, L.C.A. (Org.). Temas em educação especial: avanços recentes. São Carlos: EdUFSCar, 2004.

PEREIRA-SILVA, N .L.; DESSEN, M .A. Intervenção precoceefamília: contribuições do modelo bioecológico de Bronfenbrenner. In: DESSEN, M .A.; COSTA JUNIOR, A.L. (Org.). A ciência do desenvolvimento humano: tendências atuais eperspectivas futuras. Porto A legre: Artmed, 2005.

POLONIA, A .C.; DESSEN , M .A. Em busca de uma compreensão das relações entre família e escola. Psicologia Escolar eE ducacional, Campinas, v. 9, n. 2, p. 303-312, 2005.

POLONIA, A.C.; DESSEN, M.A.; PEREIRA-SILVA, N.L. O modelo bioecológico de Bronfenbrenner: contribuições para o desenvolvimento humano. In: DESSEN, M .A.; COSTA JUNIOR, A.L. (Org.). A ciência do desenvolvimento humano: tendências atuais e perspectivas futuras. Porto A legre: Artmed, 2005.

POTTIE, C.; SUMARAH, J. Friendships between persons with and without developmental disabilities. M ental Retardation, v. 42, n. 1, p. 55-66, 2004.

SANT'ANA , I.M. Educação inclusiva: concepção de professores e diretores. Psicologia em Estudo, Maringá, v. 10, n. 2, p. 227-234, 2005.

SILVERN, S.B. Continuity/ discontinuity between home and early childhood educational environments. The Elementary School Journal, 89,147-159, 1988.

SZYMANSKI, H. A família como um lócus educacional: perspectivas para um trabal ho psicoeducacional. Revista Brasileira de Estudos Pedagógicos, v. 81, n. 197, p. 14-25, 2000.

SZYMANSKI, H. A relação família/escola: desafios e perspectivas. Brasília: Plano Editora, 2001. 
PEREIRA-SILVA, N. L.;DESSEN, M. A.

THIN, D. Para uma análise das relações entre famílias populares e escola: confrontação entre lógi cas social izadoras. Revista Brasileira de Educação, v. 11, n. 32, p. 211-225, 2006.

WONG, S.I. At home with Down syndrome and gender. H ypatia, v. 17, p. 89-117. 2002. Disponível em 〈http:/ / www.proquest.umi.com/ pqdweb? >A cesso em 14 set 2002.

Recebido em 20/ 06/ 2007

Reformulado em 05/ 10/ 2007

A provado em 30/ 11/ 2007 